\title{
Deuterium Content in the Himalayan Precipitation at Khumbu District, Observed in 1974/1975*
}

\author{
Hisao Wushiki**
}

\begin{abstract}
A total of 129 water samples of daily precipitations were collected at Lhajung $(4420 \mathrm{~m})$ from April 1974 to March 1975. Samples were collected for 124 days within 127 wet days. The deuterium content of each sample was measured by mass spectrometry. Specially high deuterium content was found in the pre-monsoon precipitations, while lowest content in the middle of the monsoon. Annual changes of deuterium content, air temperature, and precipitation amount are clearly divided into four stages. Analyzing the long term trend of daily deuterium content, deuterium rich precipitations in pre-monsoon are attributed to the direct transport of water vapour from the Indian Ocean to the Himalayas without much rainfall on the way. The history of isotopic depletion caused by rainfall at the Indian coast is analyzed, showing the travelling time from the coast near Calcutta to the Mt. Sagarmatha region to be about four days in the wet season.
\end{abstract}

\section{Sampling and analyses}

Since 1973 we have been conducting systematic water sampling in and around Khumbu valley. At the Lhajung glacio-meteorological station a year-round rain and snow sampling was initiated as one of the main projects of the Glaciological Expedition to Nepal 1974 . Unfortunately 3 samplings were not made at the end of the project year 1974/1975, but 129 samples were collected from April 1974 to March 1975.

Two kinds of sampling methods were used: for rain, we set a $20 \mathrm{~cm}$ diameter rain gauge with a plastic sampling bottle inside. And for snow, we prepared a sampling site, covering the ground with a plastic sheet $(1.5 \times 1.5 \mathrm{~m})$ near the observation site at Lhajung.

New snow was collected with a thin wall stainless sampling cylinder $(32.2$ square $\mathrm{cm}$ in cross section) with several penetrations to the ground and was melted slowly in a plastic bag. Then each sample was transferred into a well sealed $40 \mathrm{~m} l$ bottle for storage and transportation.

Measurement of the deuterium content was done

* Glaciological Expedition of Nepal, Contribution No. 39

** Data Center for Glacier Research, Japanese Society of Snow and Ice, clo Water Research Institute, Nagoya University, Nagoya 464 at the mass spectrometry laboratory of the Tokyo Institute of Technology (Tokyo Kogyo Daigaku) in 1975. Calibration was made with the IAEA SMOW (Standard Mean Ocean Water), the deuterium content of which was reported to be $(155.76 \pm 0.05) \times 10^{-6}$ in $(\mathrm{D} / \mathrm{H})$ units (Hagemann, R. and others, 1970).

\section{Results}

Results of the deuterium content are presented in $\delta \mathrm{D}$ units, defined by

$$
\delta \mathrm{D}=\frac{\mathrm{R}-\mathrm{RSMOW}}{\mathrm{RSMOW}} \times 10 \%
$$

where $\mathrm{R}$ refers to the absolute isotope ratio (D/ H). Fig. 1 and Table 1 show the annual variation of monthly averages of $\delta \mathrm{D}$ and precipitation amount at Lhajung in 1974/1975.

There is a period of high deuterium content in the pre-monsoon and a lower level in the middle of the monsoon. The range of the annual variation of $\delta \mathrm{D}$ from April 1974 to March 1975 reached $185.6 \%$ o (the minimum of $-174.7 \%$ on July 16, 1974 and the maximum of $+10.9 \%$ on May 27) and the annual mean was $-103.4 \%$.

In Fig. 2 the monthly mean $\delta \mathrm{D}$ was plotted against the monthly precipitation amount. The wet season from June to September forms a conspicuous protruding part of the pattern. In this period the dependence of $\delta \mathrm{D}$ on the precipi- 


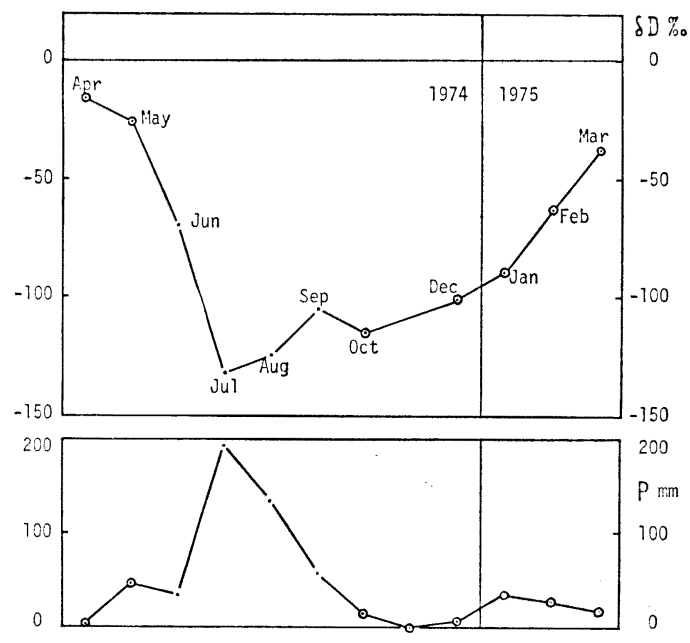

Fig. 1. Monthly average of Deuterium content (oD) and monthly precipitation (P) at Lhajung, 1974-1975.

Open circle with a dot indicates solid precipitation.

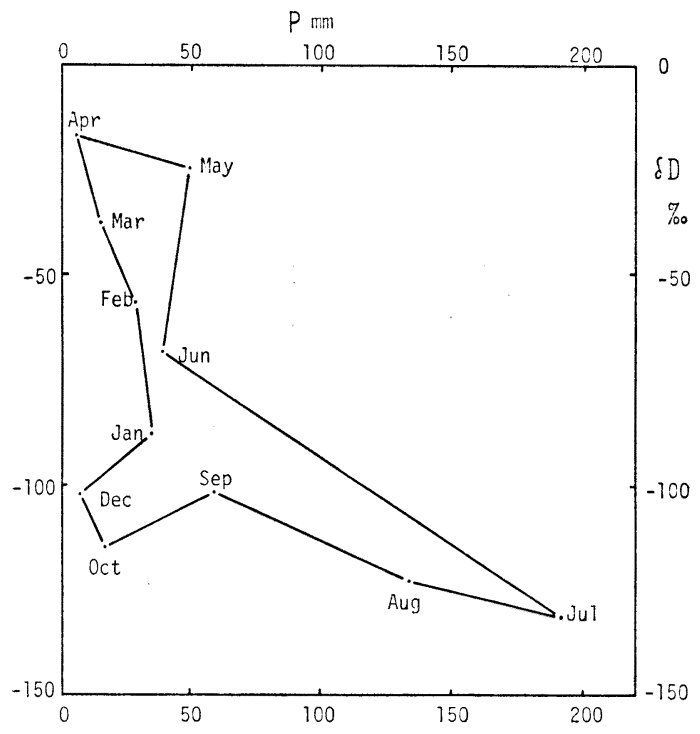

Fig. 2. Plot of monthly average of $\delta \mathrm{D}$ against precipitation.

tation amount, so called amount effect, is $-31 \%$ o per $100 \mathrm{~mm}$, which is almost on the same order as $-29 \%$ per $100 \mathrm{~mm}$ in Cuba, and Brazil calculated from the data of Dansgaard (1964).

Fig. 3 shows the relation between $\delta \mathrm{D}$ and the monthly mean air temperature. In the months from January to May we can recognize a temperature effect but it is different from the result
Table 1. Monthly and Seasonal Deuterium Coritent in Precipitations at Lhajung, Khumbu April 1974 - March 1975

\begin{tabular}{|c|c|c|c|}
\hline Month & $\begin{array}{l}\text { Monthly } \\
\text { Mean Air } \\
\text { Temperature } \\
T^{\circ} \mathrm{C}\end{array}$ & $\begin{array}{l}\text { Monthly } \\
\text { Precipitation } \\
\text { P mm }\end{array}$ & $\begin{array}{l}\text { Average D } \\
\text { Content } \\
\delta \mathrm{D} \%\end{array}$ \\
\hline 1974 April & 1.3 & 5.7 & -18.9 \\
\hline May & 2.7 & 48.5 & -25.7 \\
\hline June & 5.4 & 39.5 & -69.7 \\
\hline July & 6.3 & 192.9 & -130.4 \\
\hline August & 6.4 & 134.4 & -123.5 \\
\hline September & 4.0 & 59.7 & -103.8 \\
\hline October & 3.0 & 16.3 & -115.2 \\
\hline November & 2.1 & 0.0 & - \\
\hline December & 0.1 & 7.0 & -102.3 \\
\hline 1975 January & -7.7 & 35.1 & -88.7 \\
\hline February & -5.8 & 27.9 & -60.3 \\
\hline March & -3.2 & $15.8^{*}$ & $-37.7^{*}$ \\
\hline Annual & 1.2 & 582.8 & -103.4 \\
\hline \multicolumn{2}{|c|}{$\begin{array}{l}\text { Pre-Monsoon } \\
\text { Apr. } 18 \sim \text { July. } 10\end{array}$} & 132.2 & -5.32 \\
\hline \multicolumn{2}{|c|}{$\begin{array}{l}\text { Monsoon } \\
\text { July. } 12 \sim \text { Aug. } 29\end{array}$} & 274.7 & -137.9 \\
\hline \multicolumn{2}{|c|}{$\begin{array}{l}\text { Post-Monsoon } \\
\text { Aug. } 30 \sim \text { Oct. } 24\end{array}$} & 87.6 & -101.8 \\
\hline \multicolumn{2}{|c|}{$\begin{array}{l}\text { Winter } \\
\text { Dec. } 16 \sim \text { Apr. } 5\end{array}$} & 88.3 & -72.6 \\
\hline
\end{tabular}

* Approximate value

of Dansgaard (1964).

From these two patterns we can classify the months into four periods:

Pre-monsoon: April and May (highest enrichment of deuterium).

Monsoon: June to September (strong amount effect and much depletion in deuterium).

Post-monsoon: October to December (transitional condition).

Winter: January to March (strong temperature effect).

Fig. 4 shows the detailed change of $\delta \mathrm{D}$ and the daily precipitation in the wet season. Two interesting characteristics may be recognized.

Firstly, in the earlier part of the wet season, i.e. from April to June, several series of wet days occur more or less periodically with a surprisingly high $\delta \mathrm{D}$ at the beginning of each series and greater depletion of deuterium in the middle. The depletion of deuterium increases further in the following period of wet weather as the season advances before establishing the major wet period 


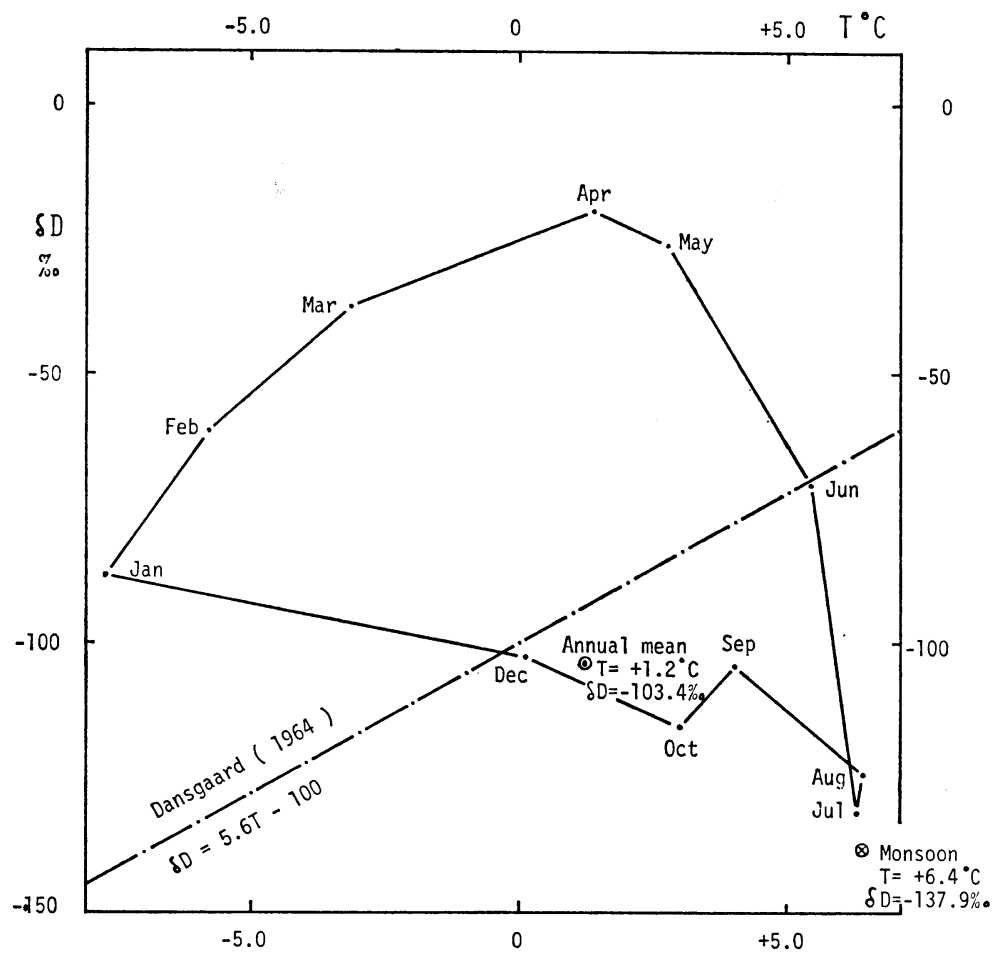

Fig. 3. Monthly averaged $\delta \mathrm{D}$ versus monthly mean air temperature.

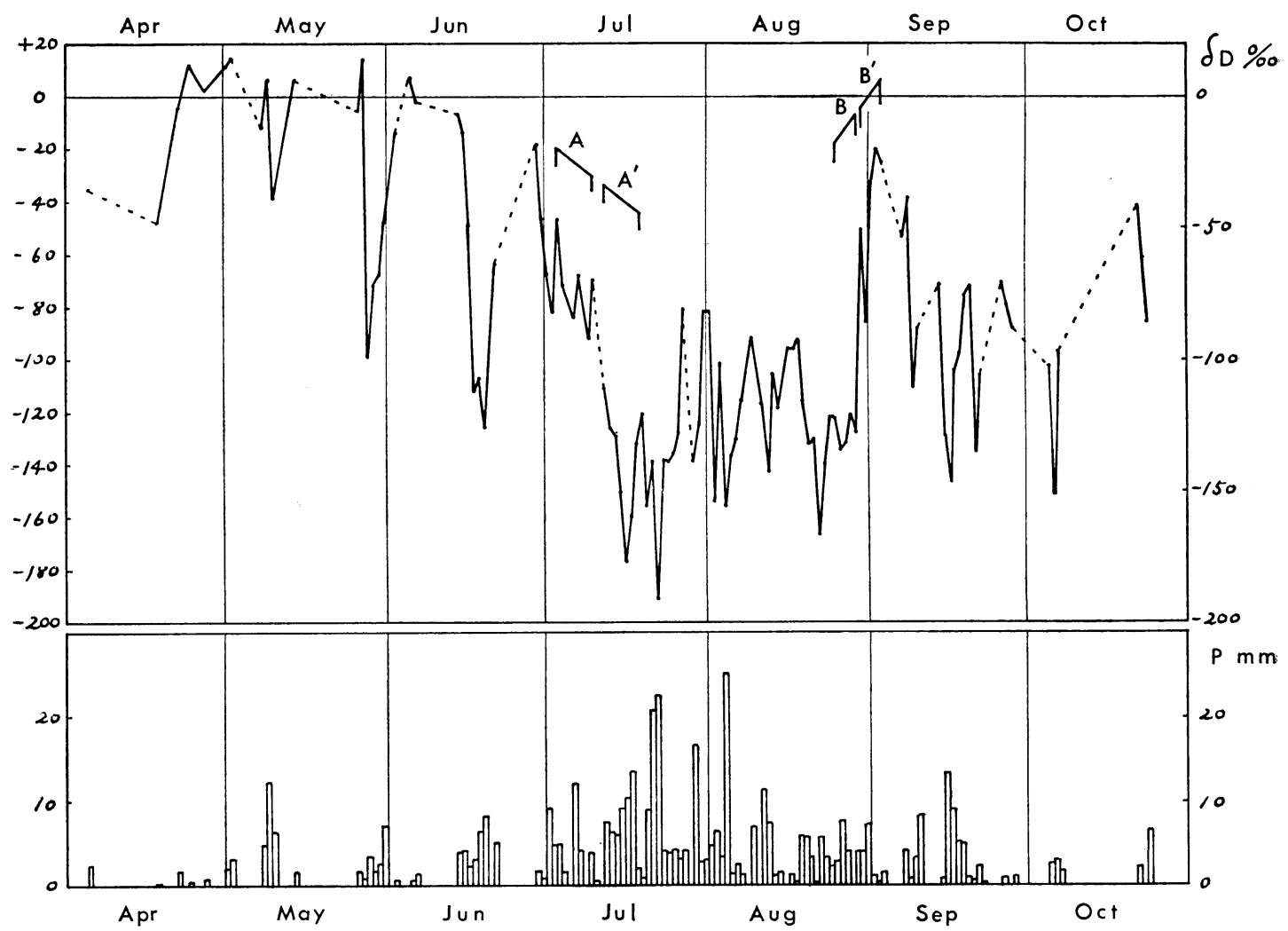

Fig. 4. Daily $\delta \mathrm{D}$ and daily precipitation in wet season. 


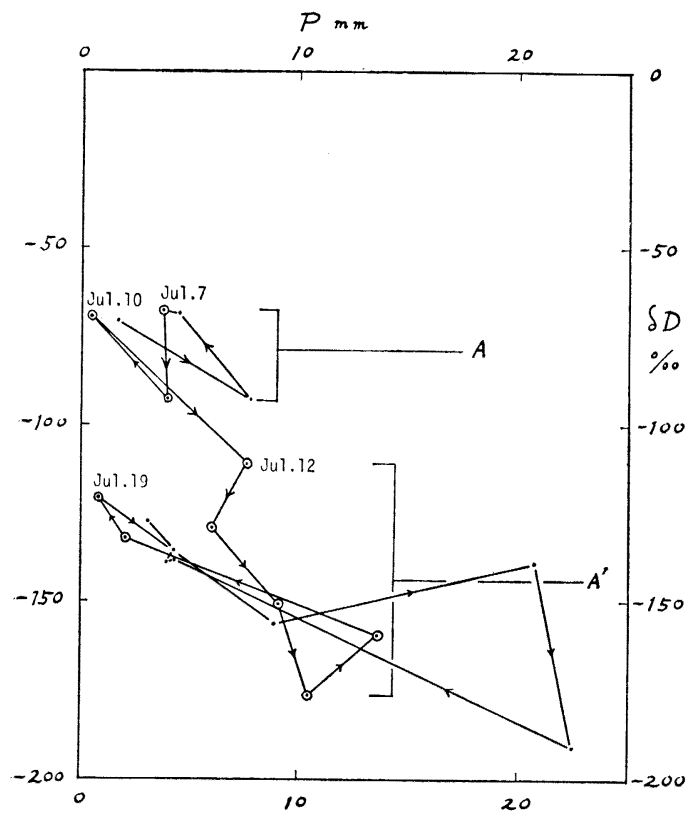

Fig. 5. Daily ôD versus daily precipitation during A-A'.

in the beginning of July.

Secondly, there are abrupt changes in the relation between $\delta \mathrm{D}$ and precipitation pattern, as are indicated $\mathrm{A}-\mathrm{A}^{\prime}$ and $\mathrm{B}-\mathrm{B}^{\prime}$ in the figure. The details of the changing patterns of A-A' and B-B' are illustrated respectively in Fig. 5 and Fig. 6. During the period from July 12 to August $30 \delta \mathrm{D}$ were less than before and after. These will suggest changes in precipitation mechanism from the sub-monsoonal to the major monsoonal one. The lower deuterium content in the major monsoon period may be caused by the removal of the heavy isotopic component in the steady monsoon rains spreading from the Indian coast to the Himalayan region as a continuous unit. In the sub-monsoon period mountain precipitation occurs in the transitional process between the direct vapour transport from the Indian Ocean and the transport with the partial removal of water vapour on the passage to the Himalayas by rains. Fig. 4, Fig. 5 and Fig. 6 indicate clearly that around Lhajung the major monsoon season was between July 12 and August 29 in 1974. As was given in Table 1, the averaged $\delta \mathrm{D}$ was $-137.9 \%$. in this period, which is quite different from $\delta \mathrm{D}$ in the preceding and following periods.

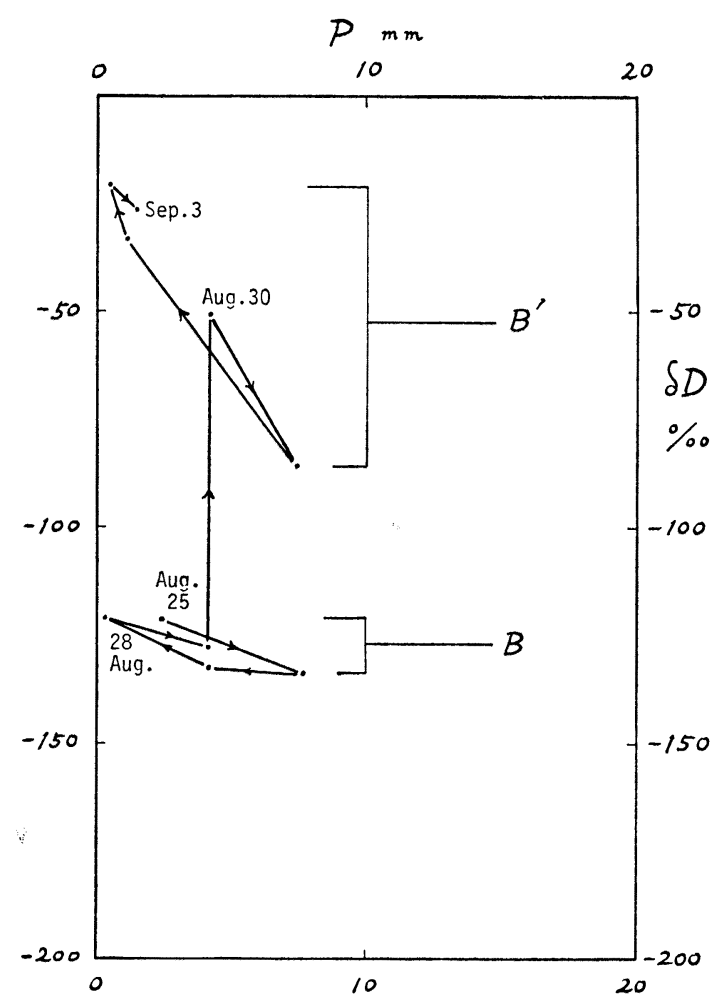

Fig. 6. Daily $\delta \mathrm{D}$ versus daily precipitation during B-B'.

3. Isotope-hydrological comparison with the surrounding region.

On the northern side of the Himalayas, stream waters of glacier origin have lower $\delta \mathrm{D}$ values than those of the southern side. In the Rongbuk river, on the northern slope of Mt. Sagarmatha (Mt. Everest), $\delta \mathrm{D}$ is about $-170 \%$. And in the Lakedouna river, on the northern slope of Mt. Gosainthan (Mt. Shisha Pangma), $\delta \mathrm{D}$ is around $-160 \%$ (Section of Chemical Geography, Institute of Geography, Academia Sinica and others, 1973).

In the Nepali side the Yalung river on the western slope of Mt. Kangchenjunga has a $\delta \mathrm{D}$ of $-105 \%$, and the Imja Khola (river) and Langtang Khola (river) have $\delta \mathrm{D}$ values of -127 $\%$ and $-112 \%$ respectively.

Although the sampling seasons of the rivers are different (Tibetan rivers were sampled in the premonsoon and Nepali rivers in the post-monsoon) and we cannot regard glacial river water to have the identical isotopic content with the present regional precipitation, the above result may reflect the difference of $\delta \mathrm{D}$ values in the precipitation between the southern and northern slopes of the 
Table 2. Deuterium Rich Precipitations in Pre-Monsoon, Lhajung, Khumbu, 1974

\begin{tabular}{|c|c|c|c|c|c|c|c|}
\hline Date & \multirow{2}{*}{$\frac{\text { Time }}{15 \mathrm{~h} \sim 17 \mathrm{~h}}$} & \multicolumn{2}{|c|}{ Precipitates } & Air temperature & Relative humidity & $\delta \mathrm{D}$ Obs. & oD Calc. \\
\hline Apr. 24 & & \multicolumn{2}{|c|}{$0.5 \mathrm{~mm}$} & $-0.6^{\circ} \mathrm{C}$ & $75 \%$ & $+9.5 \%$ & $+15.6 \%$ \\
\hline May & $13 \mathrm{~h} \sim 17 \mathrm{~h}$ & Hail then snow & 2.0 & -2.7 & 73 & +8.2 & +19.3 \\
\hline 2 & $14 \mathrm{~h} 30 \mathrm{~m} \sim 17 \mathrm{~h}$ & Hail then snow & 3.3 & -3.0 & 77 & +10.5 & +19.3 \\
\hline 9 & $14 \mathrm{~h} \sim 20 \mathrm{~h}$ & Hail then snow & 12.4 & -2.2 & 79 & +2.8 & +18.3 \\
\hline 14 & $14 \mathrm{~h} \sim 18 \mathrm{~h}$ & Sleet & 1.6 & -2.5 & 74 & +2.7 & +18.3 \\
\hline 27 & $16 \mathrm{~h} \sim$ & Rain and hail & 1. 0 & -0.2 & 68 & +10.9 & +14.7 \\
\hline June 5 & $16 \mathrm{~h} \sim$ & Rain & 0.7 & -1.2 & 76 & +5.7 & +16.5 \\
\hline
\end{tabular}

Factors for Calculation

\begin{tabular}{rr|c|c|c}
\hline \multicolumn{1}{c|}{ Date } & Fractionation factors* & Air temperature & \multirow{2}{*}{ For Indian Ocean } \\
\hline Apr. 24 & $\alpha=1.107$ & $-0.6^{\circ} \mathrm{C}$ & Surface temperature \\
May & 1 & 1.111 & -2.7 & $\mathrm{t}=29^{\circ} \mathrm{C}$ \\
& 2 & 1.111 & -3.0 & Fractionation factor* \\
& 9 & 1.110 & -2.2 & $\alpha_{0}=1.09$ \\
14 & 1.110 & -2.5 & * Merlivat, L., et al. (1963) \\
\hline
\end{tabular}

Great Himalayas as river water varies in its isotopic content within several percent of its average $\delta \mathrm{D}$ level annually. $\delta \mathrm{D}$ values of river waters will be discussed elsewhere in this issue.

In the Hidden Valley $(4900 \mathrm{~m})$, behind $\mathrm{Mt}$. Dhaulagiri, a detached party of GEN 74 collected precipitation water. Averaged $\delta \mathrm{D}$ values from July and August precipitations are $-161.9 \%$ and $-160.9 \%$ respectively. Considering the close relationship between river water and precipitation, the $\delta \mathrm{D}$ value of Hidden valley water seems to be the same as the Tibetan side water.

\section{Discussion}

We have recognized a characteristic feature of the $\delta \mathrm{D}$ change in the wet season in section 2 . Especially the high level of $\delta \mathrm{D}$ in the pre-monsoon period seems to give a clue as to the origin of the water vapour and the mechanism of water vapour transport to the Himalayas.

According to the Meteorological Atlas of IIOE (International Indian Ocean Expedition), vol. 1 and vol. 2 (1972) and the Oceanographic Atlas of IIOE (1971), in March a wind system is established to transport water vapour from the Bay of Bengal to the Himalayas. In this period, if we suppose moderate evaporation over the Indian Ocean and no precipitation and no intensive mixing with the local water vapour during transportation over the southern slope of the Himalayas, we can expect an extremely high $\delta \mathrm{D}$ value caused by the temperature difference between the sea surface where evaporatoin occurs and the mountain region where condensation occurs. $\delta \mathrm{D}$ is calculated by the equation below, derived from the equation under the Rayleigh condition (Dansgaard, 1964).

$$
\delta \mathrm{D} \text { calc. }=\left(\frac{\alpha}{\alpha_{0}}-1\right) \times 1000(\%)
$$

$\alpha$ : Isotopic fractionation factor over the Indian Ocean of SMOW

$\alpha_{0}$ : Isotopic fractionation factor at Lhajung $\alpha$ varies with the evaporation rate and the temperature at evaporation and condensation. Here we suppose a process occurs at a moderate rate so that $\alpha$ is assumed to take values in the static equilibrium condition. Over the Indian Ocean the evaporation temperature can be regarded to be the surface water temperature. The condensation temperature at Lhajung can be represented by the air temperature during the precipitation because during the monsoon season Lhajung station was within the condensation zone when precipitation occurred.

The results of the calculation based on the above assumption, are given in Table 2. Calculated values are in a fairly good agreement with the observed value. For example, on May 27, 


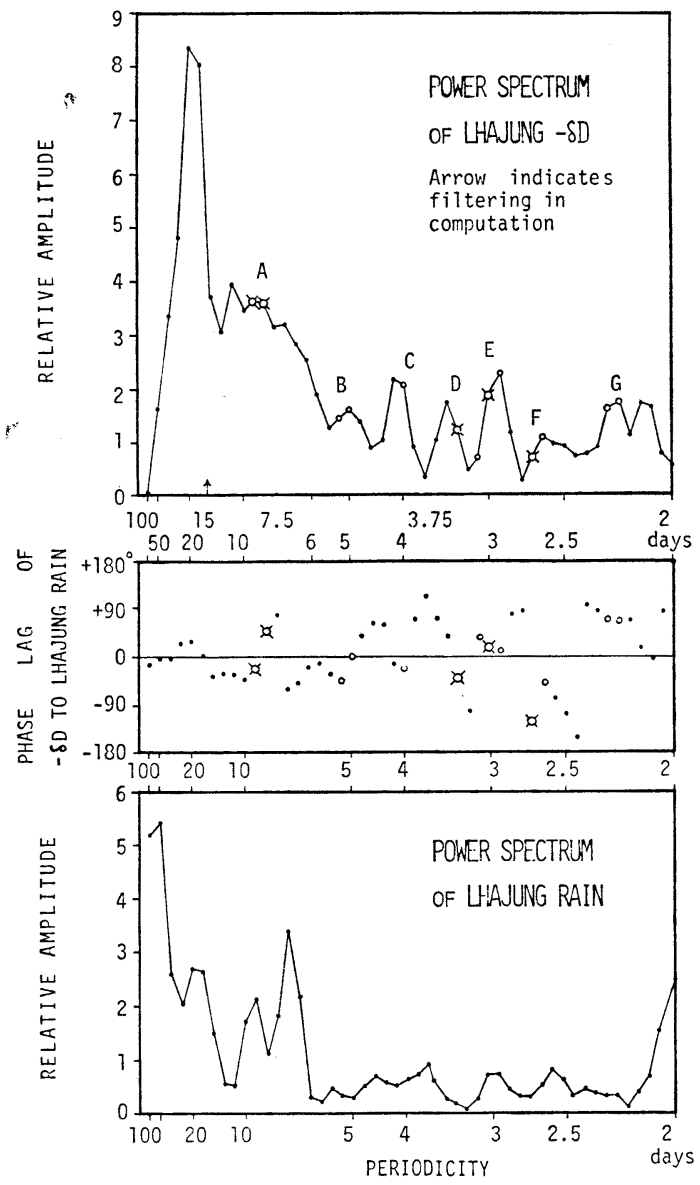

Fig. 7. Power spectrum of daily $-\delta \mathrm{D}$ and daily precipitation at Lhajung in wet season.

the observed $\delta \mathrm{D}$ was $+10.9 \%$ and the calculated $\delta \mathrm{D}$ was $+14.7 \%$. The difference is only $3.8 \%$. If we take some preceding periods of minor rainfall at the lower altitude into consideration, the results seem to support the assumption.

T. Yasunari, a GEN ' 74 member, computed relationship among $\delta \mathrm{D}$ at Lhajung and precipitation in Lhajung and Calcutta. Results of power spectrum analysis are plotted in Fig. 7 and Fig. 8.

In Fig. 7 there are several peaks on the spectrum curve which do not correlate positively with each other (between $-\delta \bar{D}$ and rain at Lhajung). Those peaks of A, B, C, D, E, F and G, in the power spectrum of Lhajung $-\delta \mathrm{D}$, are examples. Although filtering was applied to eliminate too much drift in the long term $\delta \mathrm{D}$ change by using 15 day running means, the diminishing effect on each power becomes greater only for periods longer than 15 days. Except for these peaks,

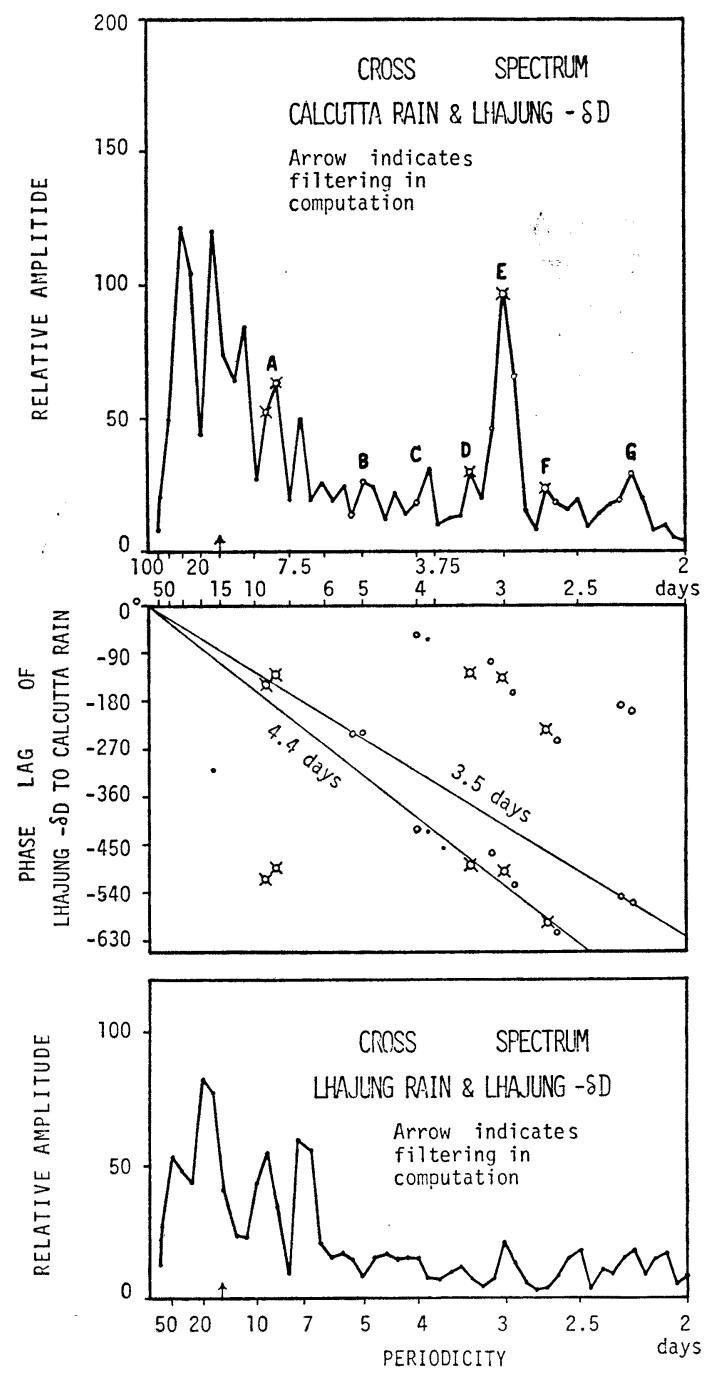

Fig. 8. Cross power spectrum of daily precipitation at Calcutta and daily $-\delta \mathrm{D}$ at Lhajung (upper).

Cross power spectrum of daily precipitation at Lhajung and dailly $-\delta \mathrm{D}$ at Lhajung. (lower).

Phase lag of Lhajung $-\delta \mathrm{D}$ to Calcutta rain (middle).

$-\delta \mathrm{D}$ and precipitation tend to be parallel. The small phase lag indicates this tendency. This also means that the local precipitation potentially charges the amount effect on $\delta \mathrm{D}$.

But when we examine the correlation between $\delta \mathrm{D}$ at Lhajung and precipitation in Calcutta shown in Fig. 8, we find better fits of those peaks than with the former combination. And the phase lags of those powers which correlate well apear 
to be on the characteristic alignments which represent two kinds of steady propagation rate of oceanic water vapour flux to the Himalayas. The fast propagation rate between Calcutta and Lhajung is 3.5 days for the rains indicated by the peaks, A, B and G in Culcutta, with periods of 8.33 days, 5.26 days and 2.22 days respectively. And the slow one is 4.4 days for the rains indicated by the peaks, D, E and F in Calcutta with periods of 3.33 days, 3.03 days and 2.70 days respectively.

As we have discussed in section 2, the amount effect has an effect on the monsoon rains. So the precipitation in the Himalayas must have a memory of the preceding rainfall in India. In July and August at $850 \mathrm{mb}$ and $700 \mathrm{mb}$ the horizontal wind blows at an averaged rate of 4 knots over Calcutta toward the north (Meteorological Atlas of IIOE, vol. 2). If this wind blows for 3.5 days or 4.4 days, it can cover $622 \mathrm{~km}$ or $781 \mathrm{~km}$. These distances are just sufficient to connect Calcutta and Lhajung. So the rainfall in the Calcutta region can throw shadow onto the Himalayan rain in its $\delta \mathrm{D}$ value after 3.5 days or 4.4 days.

\section{Concluding remarks}

Annual changes in the deuterium content in the precipitation near Mt. Sagarmatha are classified into four seasonal groups, depending upon the changes of air temperatures and precipitation amount. These four seasonal groups are premonsoon (April and May), monsoon (June to September), post-monsoon (October to December) and Winter (January to March).

Detailed analysis revealed an abrupt change in the combined pattern of deuterium content and precipitation, this change defines the major monsoon season at our observation site.

The deuterium content in monsoon precipitation at Lhajung is less depleted than that of the precipitation in the Hidden Valley which is under the influence of trans-Himalayan or Tibetan group with less $\delta \mathrm{D}$ values.

Deuterium-rich precipitation in the pre-monsoon period is attributed to the direct transportation of water vapour from the Indian Ocean almost without rainfall over the southern slope of the Himalayas. This may be the reason why sometimes deuterium-rich snows are sampled at the higher altitudes in the Himalayas as reported by the Section of Chemical Geography, Institute of Geography, Academia Sinica and others (1973).

In the monsoon season, water vapour from the Indian Ocean coast near Calcutta takes about four days before reaching the Himalayas. Memory of amount effect caused by precipitation indicates the process, which was analyzed by the cross spectrum analysis applied on $-\delta \mathrm{D}$ of Lhajung and precipitations of Calcutta and Lhajung.

\section{Acknowledgement}

The author expresses his deep gratitude to Professor S. Matsuo, Department of Chemistry, Faculty of Science, Tokyo Institute of Technology, for his warm support to the mass spectrometric analyses.

Mr. Y. Ageta, Kyoto University Yalung Kang Expedition 1973, Academic Alpine Club of Kyoto and Mr. K. Kato and Mr. S. Moribayashi. Japanese Makalu Expedition 1970, Japan Alpine Club Tokai, kindly collected and provided water samples from their expedition sites.

Mr. K. Panday, Syangboche Synoptic Station, Khumbu, Nepal and Mr. Pempa Tsering Sherpa, Chumoa Farm, Nepal, generously accepted author's request and kindly collected many water samples at their places.

\section{References}

Dansgaard, W. (1964): Stable isotopes in precipitation. Tellus, 16, 436-468.

Hagemann, R., G. Nief and E. Roth (1970): Absolute isotopic scale for deuterium Analysis of natural waters. Absolute $\mathrm{D} / \mathrm{H}$ ratio for SMOW. Tellus, 22, 712-715.

Merlivat, L., R. Botter and G. Nief (1963): Fractionnement isotopique au cours de la distillation de léau. J. Chimie Physique, 60, 56-61

Meteorological Atlas of the International Indian Ocean Expedition, Vol. 1 and Vol. 2 (1972), National Science Foundation, Washington D.C.

Oceanographic Atlas of the International Indian Ocean Expedition (1971), National Science Foundation, Washington D.C.

Section of Chemical Geography, Institute of Geography, Academia Sinica, Department of Chemistry, Pecking University, and Institute of Glacier, Permafrost and Desert Research, Academia Sinica (1973): Distribution of isotopes in some natural waters in the region north of Mt. Jolmo Lungma. Scientia Sinica, 16, 560-564. 